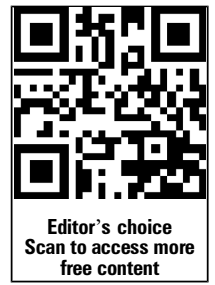

free content

\begin{abstract}
${ }^{1}$ Australian eHealth Research Centre, Commonwealth Scientific and Industrial Research Organisation, Brisbane, Queensland, Australia

${ }^{2}$ Department of Epidemiology and Preventive Medicine, Monash University, Melbourne, Australia

${ }^{3}$ School of Medicine, University of Queensland, Brisbane, Queensland, Australia

${ }^{4}$ Complex Chronic Disease Team, North Lakes Health Precinct, Metro North Hospital and Health Service, Brisbane, Queensland, Australia ${ }^{5}$ Department of Cardiology, The Prince Charles Hospital, Metro North Hospital and Health Service, Brisbane, Queensland, Australia
\end{abstract}

\section{Correspondence to} Marlien Varnfield, Australian eHealth Research Centre, Commonwealth Scientific and Industrial Research

Organisation, Level 5, UQ Health Sciences Building, 901/

16 Royal Brisbane and Women's Hospital, Herston, Brisbane, QLD 4029, Australia; marlien.varnfield@csiro.au

Received 28 February 2014 Revised 16 May 2014 Accepted 9 June 2014 Published Online First 27 June 2014

\section{SLinked}

- http://dx.doi.org/10.1136/ heartjnl-2014-306335

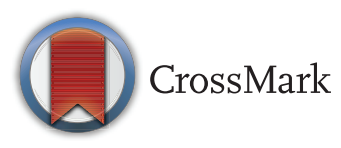

To cite: Varnfield $M_{1}$ Karunanithi M, Lee C-K, et al. Heart

2014;100:1770-1779.

\title{
Smartphone-based home care model improved use of cardiac rehabilitation in postmyocardial infarction patients: results from a randomised controlled trial
}

\author{
Marlien Varnfield, ${ }^{1,2}$ Mohanraj Karunanithi, ${ }^{1,3}$ Chi-Keung Lee, ${ }^{4}$ Enone Honeyman, ${ }^{1}$ \\ Desre Arnold, ${ }^{4}$ Hang Ding, ${ }^{1}$ Catherine Smith, ${ }^{2}$ Darren L Walters ${ }^{3,5}$
}

\section{ABSTRACT}

Objective Cardiac rehabilitation (CR) is pivotal in preventing recurring events of myocardial infarction (MI). This study aims to investigate the effect of a smartphone-based home service delivery (Care Assessment Platform) of CR (CAP-CR) on CR use and health outcomes compared with a traditional, centrebased programme (TCR) in post-Ml patients.

Methods In this unblinded randomised controlled trial, post-Ml patients were randomised to TCR $(n=60 ; 55.7$ \pm 10.4 years) and CAP-CR ( $n=60 ; 55.5 \pm 9.6$ years) for a 6-week CR and 6-month self-maintenance period. CAP$C R$, delivered in participants' homes, included health and exercise monitoring, motivational and educational material delivery, and weekly mentoring consultations. CAP-CR uptake, adherence and completion rates were compared with TCR using intention-to-treat analyses. Changes in clinical outcomes (modifiable lifestyle factors, biomedical risk factors and health-related quality of life) across baseline, 6 weeks and 6 months were compared within, and between, groups using linear mixed model regression.

Results CAP-CR had significantly higher uptake $(80 \%$ vs $62 \%)$, adherence ( $94 \%$ vs $68 \%$ ) and completion ( $80 \%$ vs $47 \%)$ rates than TCR $(p<0.05)$. Both groups showed significant improvements in 6 -minute walk test from baseline to 6 weeks (TCR: $537 \pm 86-584 \pm 99$ m; CAP-CR: $510 \pm 77-570 \pm 80 \mathrm{~m}$ ), which was maintained at 6 months. CAP-CR showed slight weight reduction (89 $\pm 20-88 \pm 21 \mathrm{~kg}$ ) and also demonstrated significant improvements in emotional state (K10: median (IQR) $14.6(13.4-16.0)$ to $12.6(11.5-13.8))$, and quality of life (EQ5D-Index: median (IQR) $0.84(0.8-0.9)$ to 0.92 $(0.9-1.0))$ at 6 weeks.

Conclusions This smartphone-based home care CR programme improved post-MI CR uptake, adherence and completion. The home-based CR programme was as effective in improving physiological and psychological health outcomes as traditional CR. CAP-CR is a viable option towards optimising use of CR services.

\section{Trial registration number}

ANZCTR12609000251224.

\section{INTRODUCTION}

Cardiac rehabilitation (CR) programmes, which involve comprehensive health behaviour interventions, are effective in reducing cardiac-related postmyocardial infarction (MI) mortality and morbidity.
Studies have demonstrated a $15-28 \%{ }^{1} 2$ decrease in all-cause mortality. Despite demonstrated benefits and guideline recommendations, CR use has been poor, particularly in women, older patients and ethnic minorities. ${ }^{3} 4$

Patient and system barriers have marred CR uptake and adherence, traditionally delivered through group-based exercise programmes in centre-based settings. ${ }^{5-8}$ Recent advances in information and communication technologies, such as smartphones and the internet, have shown potential to address some of these barriers through home-based CR programmes ${ }^{9}{ }^{10}$ and remote clinical monitoring and communication. ${ }^{11}$ One such model, the Care Assessment Platform (CAP-CR), was recently described. ${ }^{12}$

The objective of this study is to investigate whether CAP-CR is effective in improving CR use in post-MI patients compared with a traditional, centre-based programme, while demonstrating equivalent health outcomes, through a randomised controlled trial (RCT).

\section{METHODS}

\section{Study design/framework}

We conducted an unblinded RCT in four CR centres in Brisbane, Australia. The trial compared the uptake, adherence and completion of CAP-CR with that of a traditional centre-based CR programme (TCR). The study protocol,,${ }^{12}$ in compliance with the principles outlined in the Declaration of Helsinki, was approved by Redcliffe-Caboolture Ethics Committee and registered in the Australian New Zealand Clinical Trials Registry (ANZCTR12609000251224). The CAP-CR model was described previously ${ }^{12}$ and is summarised here. Due to slow recruitment, the primary outcome measure was amended from physical activity guidelines adherence to $\mathrm{CR}$ completion rates, with the primary endpoint of 60 patients recruited to each group.

\section{Study setting and participants}

Patients from Primary \& Community Health Services, Metro North Health Service District, Queensland Health, Australia, were enrolled from 2009 to 2011. All post-MI patients referred to CR were considered for participation. Subjects were excluded if they were unable to participate in selfmanagement programmes due to medical care 
needs, operate smartphone for purposes of trial (eg, vision, hearing, cognitive or dexterity impairment) or attend TCR, or were involved in another trial or had no experience with mobile/smartphones.

\section{Recruitment, randomisation and clinical review}

A project officer contacted eligible patients from a CR referral list telephonically to assess their interest to participate in a CR trial and obtained consent face-to-face. Permuted-block randomisation, by computer-generated random numbers with variable block sizes of 4, 6 and 8 using sequentially numbered opaque, sealed envelopes, was conducted prior to baseline assessment to randomise patients to one of two parallel groups: control (TCR) and intervention (CAP-CR). The project officer enrolled and assigned participants, administered baseline questionnaires and notified the CR clinician to book a baseline assessment.

Each participant underwent clinical review by their local CR centre clinician, which involved (i) collection of demographic, previous clinical history and procedural data; (ii) risk factor assessment to set individualised goals for lifestyle behaviour modification and (iii) clinical assessment (see secondary outcome measures section) at baseline, 6-week and 6-month time points. At baseline, all participants were instructed on use of the Borg's Rating of Perceived Exertion Scale (6-20 scale $)^{13}$ to monitor their exercise intensity.

Average days from cardiac event to commencing a programme were 68 days for TCR and 54 days for CAP-CR. All participants received the 'My Heart, My Life' manual:

http://www.heartfoundation.org.au/information-for-professionals/ publications/Pages/MHML.aspx

\section{Models of care}

Traditional centre-based CR programme

The TCR programme comprised of two supervised exercise and $1 \mathrm{~h}$ educational sessions on a weekly basis for 6 weeks at one of four Health Service District community centres. Participants started education sessions once enrolled to CR and twice-weekly exercise sessions commenced once centre appointments became available. Participants followed an individualised, supervised, circuit-based exercise programme of light (6-10) to moderate (11-13) intensity according to Borg's scale. The programme included cardiovascular and strengthening routines involving, for example, treadmill, rower, resistance bands, weights, squats and modified push-ups.

\section{CAP-CR programme}

The CAP-CR programme was developed according to national guidelines ${ }^{14}$ to address all components of a comprehensive CR programme. The CAP-CR platform used a smartphone for health and exercise monitoring, and delivery of motivational and educational materials to participants via text messages and preinstalled audio and video files (including understanding cardiovascular disease (CVD), symptoms and management). The platform included a web portal with participant data for mentors to provide weekly consultations.

The Australian Cardiovascular Health and Rehabilitation Association provided upfront training for mentors on CAP-CR programme delivery. Each participant was equipped with a smartphone (Nokia N96, Nokia Inc) preinstalled with health diary (WellnessDiary, Nokia Research) ${ }^{15}$ and activity monitoring (StepCounter, Nokia Research) ${ }^{15}$ applications; blood pressure (BP) monitor (AXIS Pacific C/-Delmond flexibles Pty Ltd); and weight scale (Glass Body Analysis scale, Propert). Activity monitoring (step number, duration and intensity) was automatic through the phone's in-built accelerometer. All participants received detailed programme information and $1 \mathrm{~h}$ of face-to-face training on technology use (supported by a device instruction manual) and technical phone support during the trial if required.

Mentors provided weekly scheduled telephone consultations ( $\sim 15$ min each) over 6 weeks. Participants were advised to make daily health diary entries: weight, BP, sleep duration and quality, exercise other than automatically monitored steps, stress, meals and, if relevant, alcohol consumption and smoking. Participants synchronised smartphone data via their mobile $3 \mathrm{G}$ network to a web portal (WellnessDiary Connected, Nokia Research). Mentors reviewed participants' updated data prior to weekly consultations via the web portal to provide informed, personalised feedback on progress according to goals set.

CAP-CR programme was delivered according to weekly themes and elements as outlined in figure 1. Exercise targets were at least $30 \mathrm{~min}$ of moderate activity (Borg's scale of 11-13) on most days of the week with walking as the main exercise mode.

\section{Self-management phase}

Following completion of the 6-week programme, participants from both groups were encouraged to maintain lifestyle changes achieved during CR. CAP-CR participants were able to keep their smartphones and monitoring devices throughout this selfmanagement phase for support.

\section{Outcome measures}

Primary outcome measures were uptake, adherence and completion of a CR programme. The trial commenced in May 2009 and the primary endpoint was amended in February 2011 due to the slow recruitment into the randomised study. Uptake was defined as attending baseline assessment, and at least one gym exercise session for TCR, or upload of exercise data to the web portal for CAP-CR. Adherence was defined as attendance to 4 weeks (eight or more gym sessions) for TCR or uploading of 4 weeks' exercise data for CAP-CR, and attending 6-week assessment (both groups) in uptakers, as in a similar study by Dalal and colleagues (2007). ${ }^{16}$ Completion was defined as attendance at the 6-week assessment based on those randomised to each group. Participants who did not commence or complete the CR programme had exit interviews to determine dropout reasons.

Secondary outcome measures included modifiable lifestyle factors (physical activity, nutrition, psychosocial functioning), biomedical risk factors (BP, heart rate, weight, body mass index (BMI), waist circumference (WC), lipid profile) and health-related quality of life (HRQoL). These measures were assessed at three time points (baseline, 6-week, 6-month) through questionnaires, clinical assessments and pathology testing. Questionnaires included Dietary Habits Questionnaire $(\mathrm{DHQ})^{17}$; Kessler 10 (K10) Psychological Distress Scale ${ }^{18}$; Depression, Anxiety and Stress Scale 21 (DASS21) $^{19}$ and the EQ-5D HRQoL instrument. ${ }^{20}$ Clinical assessment included anthropometry, physiological measures and functional capacity measurement (6-minute walk test $(6 \mathrm{MWT})){ }^{21}$ Pathology testing included a lipid profile. EQ-5D analysis used Time Trade-Off derived EQ-5D Weights for Australia. ${ }^{22}$

\section{Additional analysis}

Smartphone-measured and/or exercise activities

CAP-CR participants' activity monitoring application data were analysed to quantify percentage of those who adhered to daily exercise. Feedback on their perception of using the smartphone 


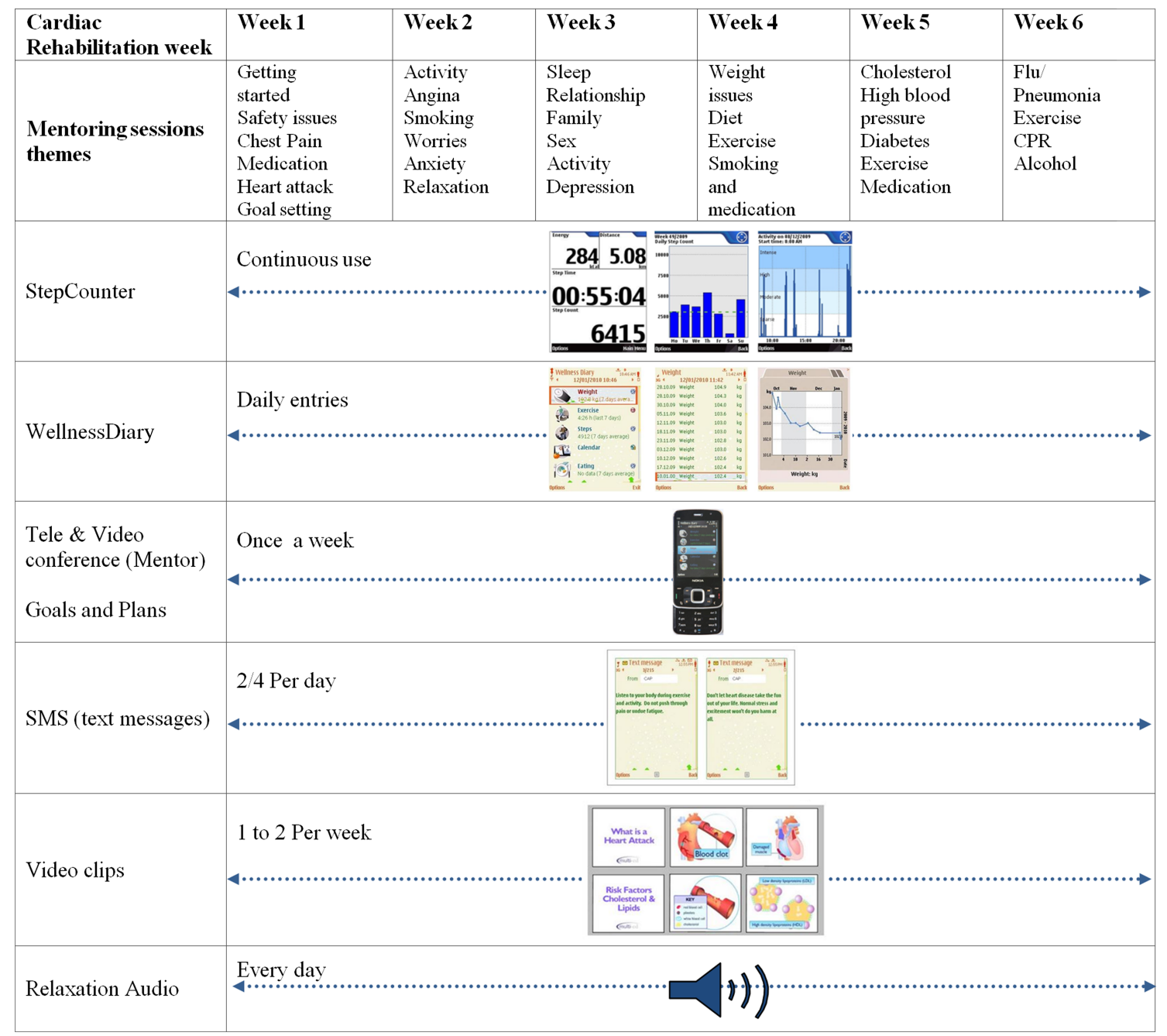

Figure 1 Frequency of expected use and delivery of applications and multimedia content, respectively, via the smartphone for the intervention group attending a 6-week home-based cardiac rehabilitation programme. Weekly themes over which mentoring sessions were conducted are also shown.

to monitor their exercise was obtained via questionnaires at 6-week and 6-month assessments.

\section{Sample size}

A previous study has shown centre-based CR completion rates of $\sim 66 \%$ and $\sim 96 \%$ for home-based programmes. ${ }^{23}$ We calculated a sample size of 55 subjects per study group, to detect a $30 \%$ difference in CR completion with $\alpha=0.01$ to achieve a power of 0.9 .

\section{Statistical methods}

Primary outcome measures 'uptake' and 'completion' were analysed on an intention-to-treat basis. 'Adherence' was only assessed in those who undertook the programme. All three outcomes were estimated in both groups and compared using relative risks (RR). Statistical significance was calculated using the two-sided Fisher's exact test.

Secondary analyses were conducted on participants with baseline, 6-week and 6-month data, without imputing for missing values, which was not more than $21 \%$, with the exception of lipid profiles. As participants' attendance to pathology tests varied largely, data selected for analysis of lipid profile were based on time frames acceptable in accordance with the assessment time points $(1$ month $<$ baseline $<1$ week, 1 week $<6$ week $<1$ month, 3 weeks $<6$-month $<1$ month), which ranged between $46 \%$ and $65 \%$. Baseline clinical characteristics were described for both groups using mean \pm SDs for continuous symmetrical variables and medians and IQR for skewed data. Categorical variables were presented as counts and percentages. Participant numbers do not always sum to group totals owing to missing data. Statistical comparisons were made between uptakers and non-uptakers from data available at randomisation. Given the potential for dropouts before baseline assessment, similar comparisons were made between the two CR groups at baseline using the cases available. We used the $\chi^{2}$ test (or Fisher's exact test) for categorical variables, the two-sample t-test for continuous variables and the Wilcoxon rank-sum test for skewed variables. Within-group differences from baseline to 6 weeks were examined using the paired t-test for symmetrical data and the Wilcoxon signed-rank test for skewed data. Differences from baseline to 6 weeks were compared between groups using analysis of covariance to take into account the baseline measurements and adjusted for age and gender.

We used linear mixed model regression to compare longitudinal changes across baseline, 6 weeks and 6 months within and between the CR groups. All statistical tests were two-tailed, and 
a $\mathrm{p}$ value of 0.05 or less was used to indicate statistical significance. Statistical analyses were performed using statistical software Stata Release V.12 (TX: StataCorp LP).

We performed a preliminary multivariate analysis to analyse the association between nine selected baseline characteristics and outcomes. In the analysis, MANOVA in SPSS V.21 was applied. The nine characteristics were (1) age, (2) gender, (3) smoking (cigarettes/day), (4) diabetes $(\mathrm{Y} / \mathrm{N}),(5)$ hypertension $(\mathrm{Y} / \mathrm{N}),(6)$ BMI, (7) alcohol (standard units/day), (8) exercise $(\mathrm{Y} / \mathrm{N}$, $150 \mathrm{~min} /$ week) and (9) 6MWT (m).

\section{RESULTS}

Of 835 patients assessed for eligibility, 120 consented and indicated intent to attend CR. Figure 2 illustrates participant recruitment, randomisation and waning throughout the trial. Randomisation yielded 60 participants per group. Mean age $(55.7 \pm 10.4$ vs $55.5 \pm 9.6$ years) and gender proportion ( $82 \%$ vs $85 \%$ male) between groups were similar.

\section{Primary outcomes}

Uptake was 1.3 times higher in CAP-CR $(48 / 60,80 \%)$ than in TCR $(37 / 60,62 \%)(\operatorname{RR} 1.30 ; 95 \%$ CI 1.03 to $1.64 ; \mathrm{p}<0.05)$. Adherence was $94 \%(45 / 48)$ in the CAP-CR group and $68 \%$ $(25 / 37)$ in the TCR group. CAP-CR participants were 1.4 times more likely to adhere to the programme (RR 1.4 ; 95\% CI 1.13 to $1.70 ; \mathrm{p}<0.05)$. CR completion in CAP-CR $(48 / 60)$ was $33 \%$ higher than TCR $(28 / 60)$ (RR $1.71 ; 95 \%$ CI 1.30 to 2.27 ; $\mathrm{p}<0.05)$. The results of the multivariate analysis to analyse the association between the nine selected baseline characteristics and outcomes did not yield any predictor of the uptake and adherence.

More than $70 \%$ of the 44 dropouts (including non-uptake or non-completion) were from TCR. Figure 3 shows primary reasons for dropout as a percentage of total dropouts. The main TCR dropout reasons were logistical (25\%) and competing life demands (14\%). Although change in circumstances was a common reason for both groups $(16 \%)$, this was mainly due to
Figure 2 Recruitment process and flow of participants through traditional cardiac rehabilitation and Care Assessment Platform-cardiac rehabilitation, intervention cardiac rehabilitation programmes.

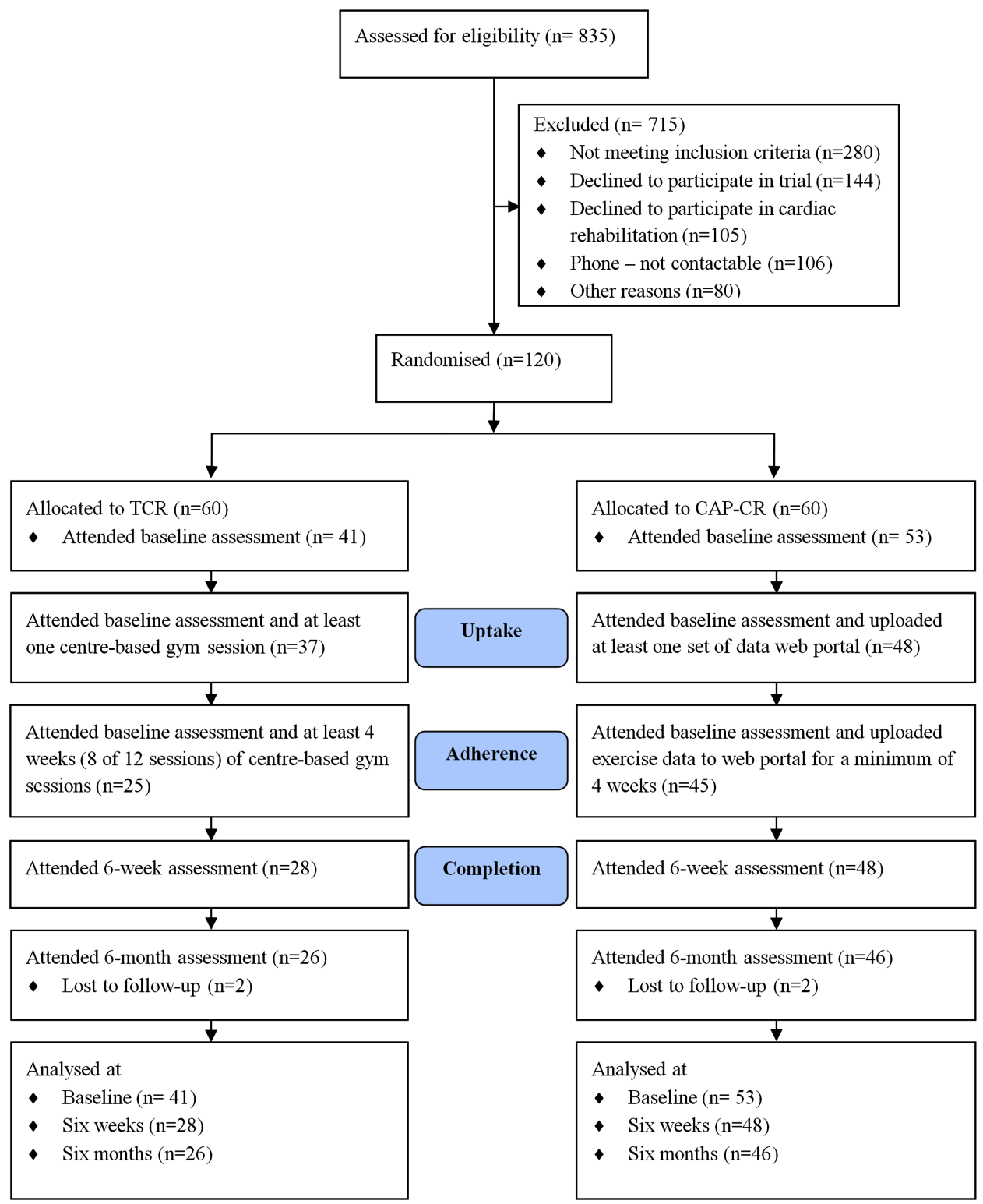




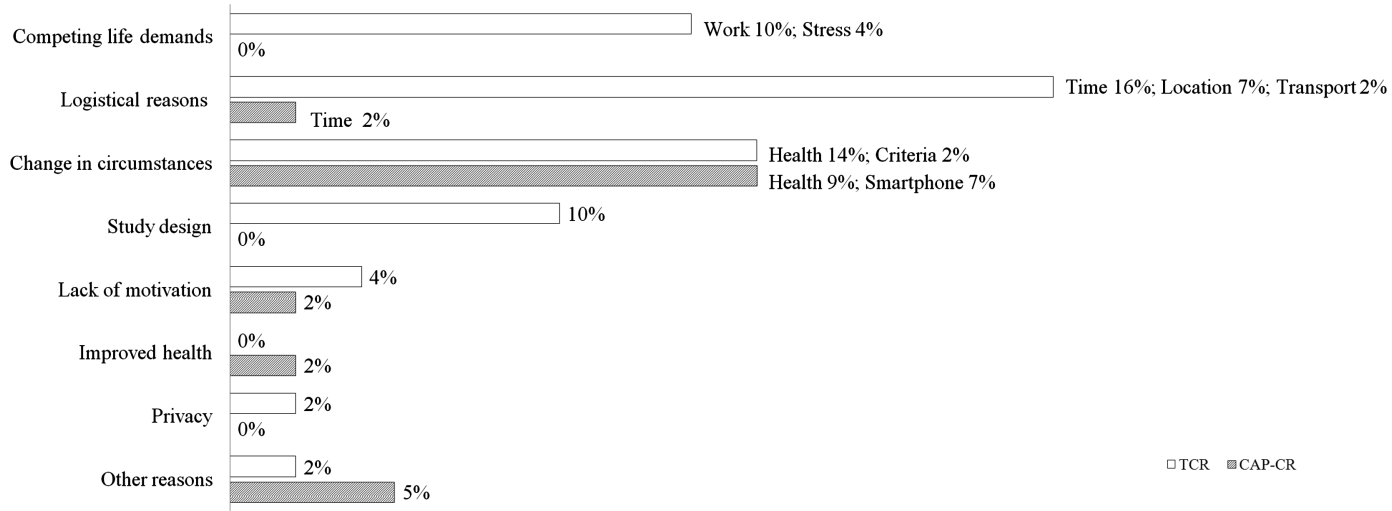

Figure 3 Percentage of dropouts from the traditional and Care Assessment Platform-cardiac rehabilitation, intervention cardiac rehabilitation programmes per primary reported reason $(n=44)$. Primary reasons for dropout categories and subcategories provided were competing life demands (work; family/care responsibilities and stress); logistical reasons (lack of time; inconvenient location; lack of transport; excessive paperwork involved and relocation); change in circumstances (deterioration in health and/or medical care needs unrelated to cardiac rehabilitation; no longer meeting inclusion/exclusion criteria; and difficulty using the smartphone due to vision, dexterity or other problems); study design (do not feel benefit from the intervention and administrative or clinical errors (eg, appointment time errors)); no longer interested/lack of motivation or commitment; no longer feel cardiac rehabilitation is required due to health improvement; concerns regarding privacy and other reasons.

deterioration in health unrelated to CR (CAP-CR 14\%; TCR 9\%). Difficulty in using IT tools was reported by $7 \%(n=3$ CAP-CR) of dropouts.

\section{Secondary outcomes}

There were no significant differences in baseline demographic and clinical characteristics of participants who commenced CR (see table 1). Both groups had an average BMI above $25 \mathrm{~kg} / \mathrm{m}^{2}$ and WC greater than $80 \mathrm{~cm}$ (females) and $94 \mathrm{~cm}$ (males), indicative of increased risk for CVD. ${ }^{14}$

\section{Change in secondary outcomes from baseline to the end of the 6-week CR programme}

Table 2 shows secondary outcome measures at baseline, 6 weeks and the mean difference between these time points $195 \% \mathrm{CI}$ and $p$ value). Both CAP-CR and TCR participants had significant improvements in dietary intake (fat, fibre and salt), mental health (DASS-depression) and triglycerides. There were significant improvements in functional capacity, via increase in 6MWT (CAP-CR (60 m); TCR (47 m)). Although DASS-depression scores were normal for both groups at baseline, both programmes were effective in reducing it further at 6 weeks. Reduction in anxiety scores (DASS) and psychological distress (K10) was found only with CAP-CR. Slight but significant improvements in weight and WC were observed in CAP-CR participants. The HRQoL (EQ5D-Index) improved significantly in CAP-CR participants compared with TCR.

Table 3 shows the difference in means between groups in their change from baseline to 6 weeks for secondary outcomes. A difference in means of zero suggests the change from baseline to 6 weeks was the same for both groups. Results of this analysis show similar size of change for most secondary outcome measures, from baseline to 6 weeks $\mathrm{CR}$, for both programmes.

Statistical significance was observed for the difference in the means in diastolic BP and EQ5D-Index for CAP-CR participants and for triglycerides in the TCR group.

\section{Six-month results}

Figure 4 shows the trend in mean values for 6MWT and lipid profiles, and median values for EQ-5D and K10 scores, from baseline to 6 weeks to 6 months. The improved 6MWT distance at 6 weeks was maintained at 6 months by both groups. Between-group differences for changes in 6MWT, low-density lipoprotein, high-density lipoprotein, EQ5D-Index or K10 were not significant at 6 months.

\section{Additional analysis}

Smartphone-measured steps and/or exercise activities.

Daily exercise (automated step counts or manually described) entries were recorded by $89 \%$ of CAP-CR participants who adhered $(n=45)$ to the CR programme. Questionnaire feedback showed $>85 \%$ of the participants found the step counter to be motivational in reaching $\mathrm{CR}$ goals.

\section{DISCUSSION}

To our knowledge, CAP is the first innovative home-based CR programme using smartphones and the internet to be clinically validated through a RCT. CAP takes advantage of the interconnectivity of smartphones and the internet to enable self-management and clinical support in delivering all core components of a comprehensive $\mathrm{CR}$ programme described in accredited CR guidelines. ${ }^{14} 24$

Markedly more participants completed CAP-CR (80\%) than TCR (47\%). CAP-CR was as effective as TCR in improving health outcomes, which included increased functional capacity (6MWT), healthier dietary intake (high fibre; low fat and salt) and decreased depression.

CAP-CR was also effective in reducing weight, WC and anxiety levels. Moreover, CAP-CR participants showed significant improvement in psychological well-being (K10 score) and HRQoL (EQ5D-Index).

Despite strong evidence of reduced mortality and morbidity resulting from $\mathrm{CR}^{12}$ in patients with $\mathrm{CVD}$, use has been poorless than $20 \%$ in the USA, UK and Australia. ${ }^{3-5}$ This has mainly been attributed to patient (dislike of group-based classes, ${ }^{7}$ lack of personalised exercise programmes, ${ }^{7}$ return to work demands, ${ }^{8}$ family commitments ${ }^{7}$ and poor motivation $^{23}$ ) and system (lack of CR programme availability and geographical inaccessibility ${ }^{6}$ ) barriers. TCR participants in our study reported similar logistical challenges (lack of time, transportation and geographical access), and competing life demands (return to work) barriers. On the other hand, difficulty using IT tools was listed as a CAP-CR dropout reason (7\%) (see figure 3). Gaining a deeper 
Table 1 Demographic and clinical characteristics by study groups at baseline

\begin{tabular}{|c|c|c|c|c|}
\hline & & TCR $(n=41)$ & CAP-CR $(n=53)$ & $p$ Value \\
\hline $\begin{array}{l}\text { Demographics } \\
\text { Mean (SD) and n (\%) }\end{array}$ & $\begin{array}{l}\text { Age (years) } \\
\text { Gender (male) }\end{array}$ & $\begin{array}{l}56.2 \pm 10.1 \\
34(83)\end{array}$ & $\begin{array}{l}54.9 \pm 9.6 \\
48(91)\end{array}$ & $\begin{array}{l}0.5 \\
0.4\end{array}$ \\
\hline $\begin{array}{l}\text { Cardiac event } \\
\mathrm{n}(\%)\end{array}$ & $\begin{array}{l}\text { STEMI } \\
\text { NSTEMI } \\
\text { Other }\end{array}$ & $\begin{array}{l}23(56) \\
18(44) \\
0\end{array}$ & $\begin{array}{l}26(49) \\
26(49) \\
1(2)\end{array}$ & $\begin{array}{l}0.6 \\
0.6 \\
0.6\end{array}$ \\
\hline Past medical & Angina & $2(5)$ & $3(6)$ & $>0.9$ \\
\hline $\begin{array}{l}\text { history (self-report) } \\
\mathrm{n}(\%)\end{array}$ & $\begin{array}{l}\text { Heart failure } \\
\text { Bypass surgery } \\
\text { Angioplasty/stent } \\
\text { Heart valve problems } \\
\text { High BP } \\
\text { High cholesterol } \\
\text { Asthma/emphysema } \\
\text { Diabetes } \\
\text { Stroke } \\
\text { Emotional problems } \\
\text { Family history } \\
\text { Hypertension } \\
\text { BMI } \\
\quad \text { Underweight (BMI <18.5) } \\
\text { Normal (BMI 18.5-24.9) } \\
\text { Overweight (BMI 25-29.9) } \\
\text { Obese (BMI >25) }\end{array}$ & $\begin{array}{l}1(2) \\
2(5) \\
33(80) \\
1(2) \\
21(51) \\
19(46) \\
2(5) \\
8(20) \\
2(5) \\
11(27) \\
28(68) \\
18(44) \\
0(0) \\
7(17) \\
19(46) \\
15(37)\end{array}$ & $\begin{array}{l}2(4) \\
6(11) \\
35(66) \\
0(0) \\
22(42) \\
29(55) \\
6(11) \\
8(15) \\
1(2) \\
17(32) \\
40(75) \\
29(55) \\
1(2) \\
8(15) \\
25(47) \\
19(36)\end{array}$ & $\begin{array}{r}>0.9 \\
0.5 \\
0.2 \\
0.4 \\
0.4 \\
0.5 \\
0.5 \\
0.6 \\
0.6 \\
0.7 \\
0.7 \\
0.3 \\
\\
>0.9 \\
>0.9 \\
>0.9 \\
>0.9\end{array}$ \\
\hline $\begin{array}{l}\text { Smoking history (self-report) } \\
\mathrm{n}(\%)\end{array}$ & $\begin{array}{l}\text { Current } \\
\text { Ex-smoker (ceased } \leq 5 \text { years) } \\
\text { Never (or ceased }>5 \text { years) }\end{array}$ & $\begin{array}{l}4(10) \\
13(32) \\
24(59)\end{array}$ & $\begin{array}{l}8(15) \\
12(23) \\
33(62)\end{array}$ & $\begin{array}{l}0.6 \\
0.6 \\
0.6\end{array}$ \\
\hline Return to work & & $19(46)$ & $23(43)$ & $>0.9$ \\
\hline $\begin{array}{l}\text { Nutrition } \\
\text { mean (SD) (n) }\end{array}$ & $\begin{array}{l}\text { DHQ } \\
\text { Fat } \\
\text { Fibre } \\
\text { Sodium } \\
\text { Alcohol }\end{array}$ & $\begin{array}{l}3.7 \pm 0.5(40) \\
3.5 \pm 0.7(40) \\
3.2 \pm 0.6(40) \\
4.2 \pm 1.4(40)\end{array}$ & $\begin{array}{l}3.8 \pm 0.4(49) \\
3.4 \pm 0.6(49) \\
3.2 \pm 0.8(49) \\
4.2 \pm 1.4(49)\end{array}$ & $\begin{array}{r}0.3 \\
0.5 \\
0.9 \\
>0.9\end{array}$ \\
\hline $\begin{array}{l}\text { Functional status } \\
\text { Mean (SD) and n (\%) (n) }\end{array}$ & $\begin{array}{l}6 \mathrm{MWT} \\
\mathrm{AA}>150\end{array}$ & $\begin{array}{l}527 \pm 86 \\
30(73)(40)\end{array}$ & $\begin{array}{l}520 \pm 78(51) \\
40(75)(48)\end{array}$ & $\begin{array}{l}0.7 \\
0.4\end{array}$ \\
\hline $\begin{array}{l}\text { Mental health } \\
\text { median (IQR) (n) }\end{array}$ & $\begin{array}{l}\text { K10 } \\
\text { DASS } \\
\quad \text { Depression } \\
\text { Anxiety } \\
\text { Stress }\end{array}$ & $\begin{array}{l}15(13-18)(40) \\
4(2-10)(40) \\
2(0-4.2)(40) \\
8(4-13)(40)\end{array}$ & $\begin{array}{l}15(13-16)(50) \\
2(2-4)(50) \\
2(1.1-4)(50) \\
6(4-8)(50)\end{array}$ & $\begin{array}{l}0.7 \\
0.3 \\
0.7 \\
0.2\end{array}$ \\
\hline $\begin{array}{l}\text { Clinical indices } \\
\text { mean }(S D)(n)\end{array}$ & $\begin{array}{l}\text { Systolic BP (mm Hg) } \\
\text { Diastolic BP (mm Hg) } \\
\text { HR } \\
\text { Weight }(\mathrm{kg}) \\
\text { BMI } \\
\text { WC (male) } \\
\text { WC (female) } \\
\text { TChol } \\
\text { LDL } \\
\text { HDL } \\
\text { Trig } \\
\text { HbA1C }\end{array}$ & $\begin{array}{l}124.9 \pm 16.1 \\
75.5 \pm 9.7 \\
64.2 \pm 12.0 \\
88.3 \pm 13.6 \\
28.9 \pm 4.1 \\
103.0 \pm 9.5(34) \\
95.2 \pm 12.2(7) \\
3.70 \pm 0.96(29) \\
2.01 \pm 0.74(28) \\
0.99 \pm 0.21(28) \\
1.51 \pm 0.98(29) \\
6.1 \pm 0.7(8)\end{array}$ & $\begin{array}{l}127.5 \pm 18.9(52) \\
75.3 \pm 9.3(52) \\
63.5 \pm 10.9(52) \\
88.8 \pm 19.1(52) \\
29.1 \pm 5.7(52) \\
101.9 \pm 13.4(48) \\
96.8 \pm 15.4(4) \\
3.47 \pm 1.14(40) \\
1.79 \pm 0.84(40) \\
1.00 \pm 0.36(40) \\
1.33 \pm 0.79(40) \\
5.8 \pm 1.4(8)\end{array}$ & $\begin{array}{l}0.5 \\
0.9 \\
0.8 \\
0.9 \\
0.9 \\
0.7 \\
0.9 \\
0.4 \\
0.3 \\
0.9 \\
0.4 \\
0.6\end{array}$ \\
\hline $\begin{array}{l}\text { Quality of life } \\
\text { median (IQR) (n) }\end{array}$ & EQ5D-Index & $0.80(0.7-1.0)(38)$ & $0.83(0.8-1.0)(48)$ & 0.5 \\
\hline
\end{tabular}

understanding of user experience challenges would help establish technology-based CR patient selection criteria.

Many investigators have tried to overcome these barriers through alternative CR delivery models, mostly in patients' home settings. ${ }^{9} 101623$ Although these studies found home-based CR programmes to be effective in improving clinical outcomes and HRQoL in patients after MI, improvements in CR use was seldom reported.

CAP-CR's ability to overcome barriers and improve CR use is clearly demonstrated by the significant increase in CR uptake and completion rates. Importantly, the 94\% adherence rate (26\% more than TCR) makes it a viable option to improve use of CR services. Although other studies ${ }^{16} 23$ that have observed home-based CR programmes have reported adherence rates of between $73 \%$ and $95 \%$, their evaluations of the exercise components have, unlike CAP-CR, relied upon self-reporting.

The majority of centre-based CR programmes are short-term and exercise-focused, as physical activity is key to CR benefits. ${ }^{25}$ CAP-CR was as effective in improving functional capacity 
Table 2 Within-group differences in risk factor outcomes at 6 weeks

\begin{tabular}{|c|c|c|c|c|c|c|c|c|c|c|c|c|c|}
\hline & \multirow[b]{2}{*}{ Outcome } & \multicolumn{5}{|c|}{ TCR } & \multirow[b]{2}{*}{$\mathrm{p}$ Value } & \multicolumn{5}{|c|}{ CAP-CR } & \multirow[b]{2}{*}{ p Value } \\
\hline & & $\mathrm{n}$ & Baseline & 6 weeks & $\begin{array}{l}\text { Mean } \\
\text { Diff }\end{array}$ & $95 \% \mathrm{Cl}$ & & $\mathbf{n}$ & Baseline & 6 weeks & $\begin{array}{l}\text { Mean } \\
\text { diff }\end{array}$ & $95 \% \mathrm{Cl}$ & \\
\hline Nutrition & DHQ & & & & & & & & & & & & \\
\hline Mean \pm SD (rating of 5 indicates & Fat & 24 & $3.8 \pm 0.6$ & $4.0 \pm 0.5$ & 0.29 & 0.1 to 0.5 & 0.005 & 40 & $3.9 \pm 0.4$ & $4.0 \pm 0.5$ & 0.15 & 0.0 to 0.3 & 0.04 \\
\hline \multirow{3}{*}{$\begin{array}{l}\text { healthy dietary behaviour) } \\
\text { hes }\end{array}$} & Fibre & 24 & $3.7 \pm 0.6$ & $3.9 \pm 0.3$ & 0.26 & 0.1 to 0.5 & 0.01 & 40 & $3.5 \pm 0.6$ & $3.8 \pm 0.6$ & 0.31 & 0.1 to 0.5 & 0.001 \\
\hline & Sodium & 24 & $3.2 \pm 0.7$ & $3.4 \pm 0.7$ & 0.27 & 0.0 to 0.5 & 0.03 & 40 & $3.3 \pm 0.8$ & $3.6 \pm 0.6$ & 0.32 & 0.1 to 0.5 & 0.004 \\
\hline & Alcohol & 24 & $4.7 \pm 0.7$ & $4.9 \pm 0.4$ & 0.17 & -0.1 to 0.4 & 0.2 & 40 & $4.3 \pm 1.3$ & $4.7 \pm 0.7$ & 0.33 & -0.0 to 0.7 & 0.06 \\
\hline $\begin{array}{l}\text { Functional Capacity } \\
\text { Mean } \pm \text { SD }\end{array}$ & $6 \mathrm{MWT}(\mathrm{m})$ & 27 & $537 \pm 86$ & $584 \pm 99$ & 47 & 22 to 71 & 0.001 & 45 & $510 \pm 77$ & $570 \pm 80$ & 60 & 47 to 73 & $<0.001$ \\
\hline Mental health & K10 score & 24 & $14.3(12.5-16.2)$ & $14.2(12-17)$ & & & 0.9 & 39 & $14.6(13.4-16.0)$ & $12.6(12-14)$ & & & 0.001 \\
\hline \multirow{3}{*}{ Mean \pm SD and median (IQR) } & DASS-Depression & 23 & $4(0-10)$ & $0(0-4)$ & & & 0.03 & 38 & $2(2-4)$ & $0(0-2)$ & & & $<0.001$ \\
\hline & DASS-Anxiety & 23 & $2(0-6)$ & $2(0-6)$ & & & 0.8 & 38 & $2(0-4)$ & $1(0-2)$ & & & 0.003 \\
\hline & DASS-Stress & 23 & $8(4-14)$ & $4(0-12)$ & & & 0.08 & 38 & $6(4-8)$ & $4(2-6)$ & & & 0.3 \\
\hline \multirow{5}{*}{$\begin{array}{l}\text { Clinical indices } \\
\text { Mean } \pm S D\end{array}$} & Systolic BP & 26 & $124.0 \pm 14.4$ & $124.4 \pm 15.0$ & 0.42 & -5.4 to 6.2 & 0.9 & 46 & $125.9 \pm 16.5$ & $123.1 \pm 17.12$ & -2.72 & -6.6 to 1.1 & 0.2 \\
\hline & Diastolic BP & 26 & $74.8 \pm 9.5$ & $76.2 \pm 7.6$ & 1.39 & -3.1 to 5.8 & 0.5 & 46 & $74.2 \pm 8.7$ & $71.7 \pm 8.9$ & -2.41 & -4.9 to 0.0 & 0.05 \\
\hline & HR (resting) & 26 & $60.5 \pm 9.8$ & $63.3 \pm 11.7$ & 2.81 & -0.4 to 6.0 & 0.08 & 46 & $63.5 \pm 11.2$ & $64.3 \pm 10.8$ & 0.78 & -1.5 to 3.0 & 0.5 \\
\hline & Weight (kg) & 26 & $88.9 \pm 12.0$ & $89.0 \pm 12.0$ & $0.18 \%$ * & -1.1 to 1.4 & 0.8 & 46 & $89.1 \pm 20.2$ & $88.3 \pm 20$ & $-0.97 \%$ * & -1.8 to -0.1 & 0.02 \\
\hline & WC $(\mathrm{cm})$ & 26 & $101.8 \pm 9.5$ & $100.7 \pm 8.7$ & -1.15 & -2.7 to 0.4 & 0.1 & 46 & $102.0 \pm 14.2$ & $101.1 \pm 14.4$ & -0.97 & -1.9 to -0.1 & 0.04 \\
\hline \multirow{4}{*}{$\begin{array}{l}\text { Lipid profile } \\
\text { Mean } \pm \text { SD }\end{array}$} & TChol & 15 & $3.59 \pm 1.13$ & $2.96 \pm 0.66$ & -0.63 & -1.2 to -0.0 & 0.04 & 31 & $3.48 \pm 1.16$ & $3.22 \pm 0.81$ & -0.26 & -0.6 to 0.0 & 0.07 \\
\hline & LDL & 13 & $2.0 \pm 0.91$ & $1.61 \pm 0.53$ & -0.39 & -1.0 to 0.2 & 0.2 & 31 & $1.79 \pm 0.86$ & $1.66 \pm 0.51$ & -0.13 & -0.4 to 0.1 & 0.3 \\
\hline & HDL & 13 & $0.94 \pm 0.20$ & $0.92 \pm 0.20$ & -0.01 & -0.1 to 0.1 & 0.8 & 31 & $1.03 \pm 0.37$ & $0.99 \pm 0.38$ & 0.03 & -0.0 to 0.1 & 0.4 \\
\hline & Trig & 15 & $1.55 \pm 1.16$ & $1.05 \pm 0.69$ & -0.51 & -0.8 to -0.2 & 0.006 & 31 & $1.32 \pm 0.79$ & $1.13 \pm 0.70$ & -0.19 & -0.4 to -0.0 & 0.03 \\
\hline Quality of Life & EQ5D-Index & 23 & $0.83(0.8-0.9)$ & $0.82(0.7-0.9)$ & & & 0.7 & 38 & $0.84(0.8-0.9)$ & $0.92(0.9-1.0)$ & & & $<0.001$ \\
\hline EQ-5D & & & & & & & & & & & & & \\
\hline Median (IQR) & & & & & & & & & & & & & \\
\hline
\end{tabular}

*Percentage weight change compared to initial weight.

6MWT, 6-Minute Walk Test (m); BP, blood pressure; CAP-CR, Care Assessment Platform-Cardiac rehabilitation; DASS, Depression, Anxiety and Stress Scale 21; DHQ, Dietary Habits Questionnaire; HDL, high-density lipoprotein (mmol/L); HR, heart rate

(resting bpm); K10, Kessler 10 (score); LDL, low-density lipoprotein (mmol/L); PhysAct, physical activity; TChol, total cholesterol (mmol/L); TCR, traditional cardiac rehabilitation; Trig, triglycerides(mmol/L); WC, waist circumference. 
Table 3 Between-group comparisons of secondary outcomes (baseline to 6 weeks)

\begin{tabular}{|c|c|c|c|}
\hline & & $\begin{array}{l}\text { Adjusted mean difference } \\
\text { at } 6 \text { weeks }(95 \% \mathrm{Cl})\end{array}$ & $\begin{array}{l}p \text { Value for } \\
\text { analysis of } \\
\text { covariance }\end{array}$ \\
\hline Nutrition & $\begin{array}{l}\text { DHQ } \\
\text { Fat } \\
\text { Fibre } \\
\text { Sodium } \\
\text { Alcohol }\end{array}$ & $\begin{array}{r}0.09(-0.12 \text { to } 0.30) \\
0.04(-0.17 \text { to } 0.24) \\
-0.11(-0.38 \text { to } 0.16) \\
0.09(-0.20 \text { to } 0.37)\end{array}$ & $\begin{array}{l}0.4 \\
0.7 \\
0.4 \\
0.6\end{array}$ \\
\hline $\begin{array}{l}\text { Functional } \\
\text { capacity }\end{array}$ & 6MWT & $-10.19(-35.0$ to 14.63$)$ & 0.4 \\
\hline $\begin{array}{l}\text { Mental } \\
\text { heath }\end{array}$ & $\begin{array}{l}\text { K10 } \\
\text { DASS-depression } \\
\text { DASS-anxiety } \\
\text { DASS-stress }\end{array}$ & $\begin{array}{r}1.85(-0.11 \text { to } 3.81) \\
0.90(-0.77 \text { to } 2.57) \\
1.63(-0.21 \text { to } 3.46) \\
-1.00(-3.81 \text { to } 1.81)\end{array}$ & $\begin{array}{l}0.1 \\
0.3 \\
0.1 \\
0.5\end{array}$ \\
\hline Parameters & $\begin{array}{l}\text { Systolic BP } \\
\text { Diastolic BP } \\
\text { HR } \\
\text { Weight }\end{array}$ & $\begin{array}{l}2.53(-3.63 \text { to } 8.68) \\
4.19(0.44 \text { to } 7.93) \\
1.40(-2.23 \text { to } 5.03) \\
0.96(-0.28 \text { to } 2.20)\end{array}$ & $\begin{array}{l}0.4 \\
0.03 \\
0.4 \\
0.1\end{array}$ \\
\hline & WC & $-0.18(-1.85$ to 1.48$)$ & 0.8 \\
\hline Lipid profile & TChol & $-0.26(-0.65$ to 0.13$)$ & 0.2 \\
\hline & LDL & $-0.11(-0.42$ to 0.20$)$ & 0.5 \\
\hline & HDL & $-0.06(-0.18$ to 0.06$)$ & 0.3 \\
\hline & Trig & $-0.26(-0.51$ to -0.01$)$ & 0.04 \\
\hline & $\mathrm{HbA1C}$ & $-0.31(-1.13$ to 0.52$)$ & 0.4 \\
\hline $\begin{array}{l}\text { Quality of } \\
\text { life }\end{array}$ & EQ5D-Index & $-0.08(-0.14$ to -0.02$)$ & 0.01 \\
\hline
\end{tabular}

(6MWT) as TCR, even though no supervised or structured exercise sessions were provided. This may have been mediated by biofeedback from the activity monitoring application. CAP-CR participants' feedback that the activity monitoring application was a key motivating factor supports this assumption.

Participants in both groups were overweight at the start of our study (83\%), and similar to rates reported previously for participants entering CR. ${ }^{26}$ The slight but significant weight loss experienced by CAP-CR participants suggests the programme could be useful in combating obesity in patients with CVD.

Psychological morbidity is common post-MI, with high levels of anxiety and depression as predictors of poorer outcomes. ${ }^{27}$ Dalal and colleagues demonstrated that telephone-assisted, home-based CR was as effective in improving depression and anxiety as hospital-based CR. ${ }^{16} \mathrm{~A}$ recent meta-analysis ${ }^{28}$ showed most CR programmes delivered at home significantly improved depression symptoms in adults over 64 years. Our study demonstrated CAP-CR was effective in significantly reducing DASS-depression scores, as well as DASS-anxiety scores. Moreover, the improved 6-week psychological distress (K10) score remained significant and maintained below baseline at 6 months (see figure 4).

Overall HRQoL is also imperative to survival rates and an important measure in economic analysis of societal impact. A systematic review ${ }^{29}$ of CR effects on HRQoL reported that home-based and centre-based interventions were equally effective in physical and psychological domains. In our study, CAP-CR improved participants' HRQoL significantly more than TCR. Factors contributing to this improvement might include the reduced travel burden and attending to $\mathrm{CR}$ at home without competing life demands.

A full cost-effectiveness analysis was beyond the original scope of the study. However, using 2010 Australian health economics data, ${ }^{30}$ CAP-CR would result in 3108 more people completing CR annually, resulting in 622 less admissions and the same reduction in deaths (assuming 29\% referral rate, 33\% completion rate and $20 \%$ reduction in mortality and admission
Figure 4 (A) Line graphs showing changes in mean \pm SD for 6 Minute Walk Test, low-density lipoprotein and high-density lipoprotein over 6 months for traditional cardiac rehabilitation and Care Assessment Platform-cardiac rehabilitation, intervention cardiac rehabilitation participants. (B) Box plots of EQ5D-index (median values) and Kessler 10 scores for traditional cardiac rehabilitation and Care Assessment Platform-cardiac rehabilitation, intervention cardiac rehabilitation participants.
A

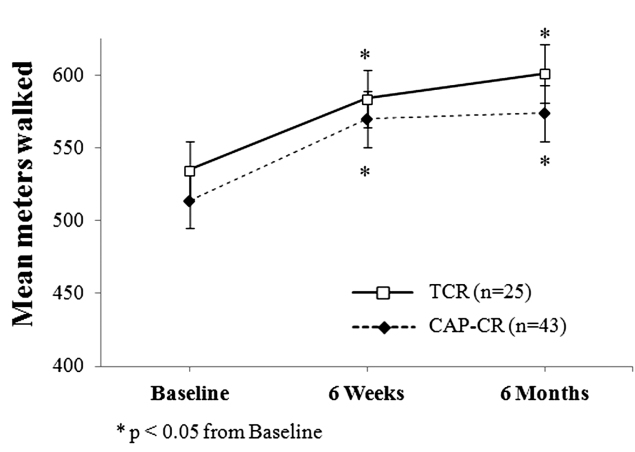

B EQ5D-index

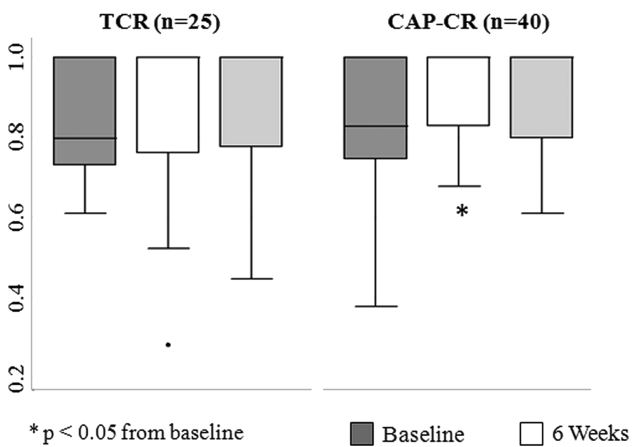

\section{LDL and HDL profile}

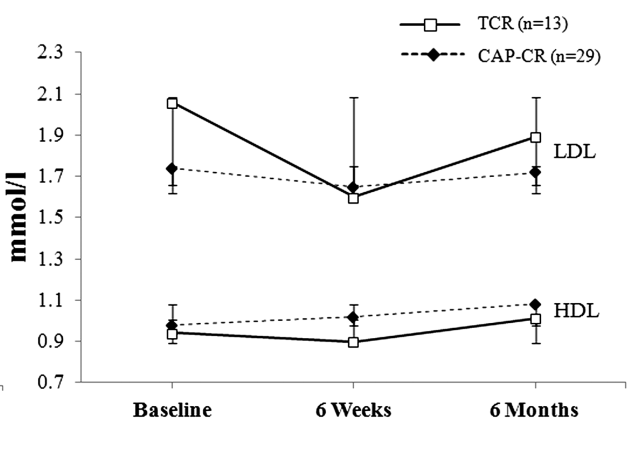

Kessler 10 Score

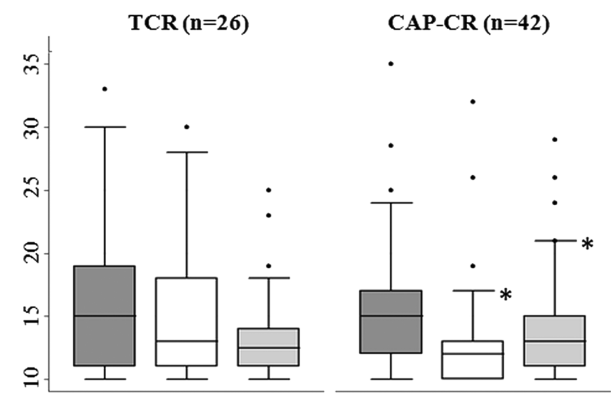


rates following CR) in the Australian population, resulting in AU\$16.6 million readmission cost savings.

\section{LIMITATIONS}

A major limitation of this study is the small sample size. Although powered for completion rate outcome, it was too small to demonstrate functional capacity outcomes, particularly due to considerable dropouts. CAP-CR reduced waiting time from referral to commencing CR by 2 weeks on average. The shorter recovery time may have influenced outcomes. This study, however, did not observe the effect of this outcome between the two groups. Based on CAP-CR's significant improvements in uptake and adherence, future studies should investigate its effectiveness on functional capacity in a larger sample. This study focused only on patients referred to CR post-MI and did not address all patients eligible for CR. Furthermore, having a preference group, as described in Dalal et $a l,{ }^{16}$ would have enhanced our study, as a better measure of uptake and adherence in a real life, based on personal preferences and choice given in CR service. Willingness to be randomised to specific treatment strategy did impact on recruitment into the trial and explains to some degree the slow recruitment of eligible patients. While a blinded RCT is preferred in validating treatments, it is hard to blind patients to new treatment modes.

\section{CONCLUSION}

We have validated a smartphone-enabled home care CR model for use and clinical effectiveness through a RCT. Findings demonstrated that CAP-CR was successful in overcoming some of the key barriers to use of a CR programme, with improved uptake, adherence and completion. Importantly, CAP-CR improved participants' health outcomes to the same extent as TCR, including improvements in physical and psychological well-being. CAP-CR was also successful in the improvement and maintenance of participants' HRQoL during and after the 6-week programme. Therefore, CAP-CR is an effective

\section{Key messages}

\section{What is known on this subject?}

Cardiac rehabilitation is a coordinated, multifaceted intervention designed to optimise a cardiac patient's physical, psychological and social functioning, thereby reducing morbidity and mortality. Despite these benefits, use of these programmes is poor due to patient and system barriers. Many investigators have tried to overcome these barriers through alternative cardiac rehabilitation (CR) delivery models, mostly in patients' home settings.

\section{What might this study add?}

Care assessment platform is a home care model that takes advantage of the interconnectivity of smartphones and the internet to employ self-management and clinical support to deliver all core components of a comprehensive CR programme, as outlined in accredited CR guidelines. This study is the first to validate a mobile health service delivery model for home CR.

\section{How might this impact on clinical practice?}

Providing a smartphone-enabled home-based CR programme could enhance patient choice if provided as an option within CR services, improve CR use and enable more efficient healthcare spending. alternative model for CR delivery for patients unable to access traditional CR. Furthermore, CAP-CR is an enabler for rehabilitation maintenance beyond the short-term 6-week programme.

Acknowledgements We acknowledge Nokia Research for donating the smartphones and software applications, Australian Cardiac Rehabilitation Association for reviewing CAP-CR for compliance with national guidelines and the project group and clinicians at Metro North Hospital and Health Service. We wish to specifically acknowledge the contributions by Gavin Brealey, Anita Keightley and Marie Steer. We also acknowledge Antti Sarela (goAct) who contributed in design and development of the CAP-CR model and the RCT

Contributors MK and DWL were instrumental in study conception. MV, MK, CL, $\mathrm{HD}$ and DLW designed the study. MV, CL, HD, MK and DLW conceived the idea for an article. CS was the study statistician. MV, CL, HD and DA implemented and conducted the study. MV, CL, DA and EH collected data. MV and $C L$ project managed the study. MV, MK, CL, EH, HD, DA, CS and DLW analysed and interpreted the study data. MV, $C L, E H, H D$ and $M K$ reviewed the literature. MV drafted the first manuscript. MV, MK, CL, EH, HD, DA, CS and DLW critically reviewed the manuscript and approved the final version for submission. MK accepts overall responsibility for the accuracy of the data, its analysis and this manuscript.

Funding Funding for this project was provided through a Joint Venture between Australian eHealth Research Centre and Queensland Health.

\section{Competing interests None.}

Ethics approval Redcliffe-Caboolture Ethics Committee, Northside Health Service District.

Provenance and peer review Not commissioned; externally peer reviewed.

Data sharing statement Patient-level data available from the corresponding author at marlien.varnfield@csiro.au. Participants only gave informed consent for anonymised patient-level data sharing with the research team and publications to include aggregate data, but the presented data are anonymised and risk of identification is low.

\section{REFERENCES}

1 Clark AM, Hartling L, Vandermeer B, et al. Meta-analysis: secondary prevention programs for patients with coronary artery disease. Ann Intern Med 2005; 143:659-72.

2 Taylor R, Brown A, Ebrahim S, et al. Exercise-based rehabilitation for patients with coronary heart disease: systematic review and meta-analysis of randomized controlled trials. Am J Med 2004;116:682-92.

3 Suaya JA, Shepard DS, Normand SL, et al. Use of cardiac rehabilitation by Medicare beneficiaries after myocardial infarction or coronary bypass surgery. Circulation 2007;116:1653-62.

4 British Heart Foundation. National Audit of Cardiac Rehabilitation (NACR). 2012. http://www.bhf.org.uk/pdf/NACR_Report_Final_2012.pdf

5 Scott IA, Lindsay KA, Harden HE. Utilisation of outpatient cardiac rehabilitation in Queensland. Med J Aust 2003;179:341-5.

6 Gurewich D, Prottas J, Bhalotra S, et al. System-level factors and use of cardiac rehabilitation. J Cardiopulm Rehabil Prev 2008;28:380-5.

7 Clark AM, Barbour RS, White M, et al. Promoting participation in cardiac rehabilitation: Patient choices and experiences. J Adv Nurs 2004;47:5-14.

8 Cooper AF. Factors associated with cardiac rehabilitation attendance: a systematic review of the literature. Clin Rehabil 2002;16:541-52.

9 Jolly K, Taylor RS, Lip GY, et al. Home-based cardiac rehabilitation compared with centre-based rehabilitation and usual care: a systematic review and meta-analysis. Int J Cardiol 2006;111:343-51.

10 Dalal HM, Zawada A, Jolly K, et al. Home based versus centre based cardiac rehabilitation: Cochrane systematic review and meta-analysis. BMJ 2010;340:b5631.

11 Neubeck L, Redfern J, Fernandez R, et al. Telehealth interventions for the secondary prevention of coronary heart disease: a systematic review. Eur J Cardiovasc Prev Rehabil 2009:16:281-9.

12 Walters D, Sarela A, Fairfull A, et al. A mobile phone-based care model for outpatient cardiac rehabilitation: the care assessment platform (CAP). BMC Cardiovasc Disord 2010;10:5

13 Borg GA. Psychophysical bases of perceived exertion. Med Sci Sports Exerc 1982;14:377-81.

14 National Heart Foundation of Australia and the Cardiac Society of Australia and New Zealand. Reducing risk in heart disease 2007 (updated 2008).

15 Mattila M, Pärkkä J, Hermersdorf $M$, et al. Mobile diary for wellness managementresults on usage and usability in two user studies. IEEE T Inf Technol 2008;12:501-12.

16 Dalal HM, Evans PH, Campbell JL, et al. Home-based versus hospital-based rehabilitation after myocardial infarction: a randomized trial with preference arms-Cornwall Heart Attack Rehabilitation Management Study (CHARMS). Int $J$ Cardiol 2007:119:202-11. 
17 McKellar S, Horsley P, Chambers R, et al. Development of the diet habits questionnaire for use in cardiac rehabilitation. Aust J Prim Health 2008;14:43-7.

18 Kessler RC, Andrews G, Colpe LJ, et al. Short screening scales to monitor population prevalences and trends in non-specific psychological distress. Psychol Med 2002:32:959-76.

19 Lovibond PF, Lovibond SH. The structure of negative emotional states: comparison of the Depression Anxiety Stress Scales (DASS) with the Beck Depression and Anxiety Inventories. Behav Res Ther 1995;33:335-43.

20 EuroQol Group. EuroQol-a new facility for the measurement of health-related quality of life. Health Policy 1990;16:199-208.

21 Lipkin $D$, Scriven $A$, Crake $T$, et al. Six minute walking test for assessing exercise capacity in chronic heart failure. Br Med J (Clin Res Ed) 1986:292:653-5.

22 Viney R, Norman R, King MT, et al. Time trade-off derived EQ-5D weights for Australia. Value Health 2011:14:928-36.

23 Jolly K, Lip GY, Taylor RS, et al. The Birmingham Rehabilitation Uptake Maximisation study (BRUM): a randomised controlled trial comparing home-based with centre-based cardiac rehabilitation. Heart 2009;95:36-42.
24 Balady GJ, Williams MA, Ades PA, et al. Core components of cardiac rehabilitation/ secondary prevention programs: 2007 update. Circulation 2007;115:2675-82.

25 Clark AM, Hartling L, Vandermeer B, et al. Secondary prevention programmes for coronary heart disease: a meta-regression showing the merits of shorter, generalist, primary care-based interventions. Eur J Cardiovasc Prev Rehabil 2007; 14:538-46

26 Savage PD, Ades PA. The obesity epidemic in the United States: role of cardiac rehabilitation. Coron Artery Dis 2006;17:227-31.

27 Thornton LA. Depression in post-acute myocardial infarction patients. J Am Acad Nurse Pract 2001;13:364-7.

28 Gellis ZD, Kang-Yi C. Meta-analysis of the effect of cardiac rehabilitation interventions on depression outcomes in adults 64 years of age and older. Am J Cardiol 2012;110:1219-24.

29 Shepherd CW, While AE. Cardiac rehabilitation and quality of life: a systematic review. Int I Nurs Stud 2012;49:755-71.

30 Deloitte Access Economics. ACS in perspective: the importance of secondary prevention 2011. 